\title{
Investigations for Quasi-Z Source Based Cascaded H-bridge Inverter With Unequal Input Voltages
}

\author{
${ }^{* 1}$ Alviya Mahevash, ${ }^{2}$ Sumant. G. Kadwane, ${ }^{3}$ S. P. Adhau \\ 1,2,3 Yeshwantrao Chavan College of Engineering Wanadongri, Nagpur. \\ Email: 1alviyamahevash95@gmail.com, ${ }^{2}$ sgkadwane@gmail.com, ${ }^{3}$ adhau_sp@yahoo.co.in
}

Received: 06th October 2019, Accepted: 20th November 2019, Published: 31st December 2019

\begin{abstract}
Owing to the advantages of the distributed generators and hybrid energy system, the inverter with more than one dc source is now increasingly investigated. This paper presents a control scheme for single phase quasi $Z$ source inverter (qZSI) network based on Cascaded H-bridge five level based boost inverter using the Simple Boost Control (SBC). The harmonic analysis is carried out and simulated results are presented for equal and unequal dc input voltages across the inverter. The successful application SBC for closed loop control of qZSI based converter is the primary contribution of this work. The theoretical analysis of the switching states, PWM control scheme is presented with harmonic analysis.
\end{abstract}

\section{Keywords}

Cascaded H-Bridge (CHB), Quasi-Z Source Inverter (qZSI), Simple Boost Control (SBC), Voltage Source Inverter (VSI), Shoot Through (ST).

\section{Introduction}

The multilevel inverters holds much more advances and challenges for the power conversions and has the advantage over the three level pulse width modulation particularly with the invent of renewable energy.

The multilevel inverters have a several advantages such as improved quality output waveform, lower total harmonic distortion (THD), low electromagnetic interference and smaller filter size [1]. Using the additional boost converter it increases the cost and component count with lower efficiency [2].

There are three general topologies of multilevel inverters, such as flying capacitors, neutral point clamed, and cascaded $\mathrm{H}$-bridge (CHB) inverters. The CHB inverter has advantage as compared to the other topologies due to its uniqueness in modularity and independent input sources. An effective control method for control of open loop CHB is presented in most of the literatures and particularly increasingly applied to solar and renewable energy applications [3]. The multilevel inverters are now used for majority of power system applications [4,5]. A class of Quasi Z source inverter (qZSI) with the acceptance of symmetrical shoot through is been addressed in [6,7].

In conventional voltage source inverter (VSI) the obtainable ac output voltage is usually lower than the de input voltage, therefore an additional dc-dc boost converter is needed to generate the desired ac output voltage [7] And this extra boost converter increases the complexity of power converter and this is replaced by the qZSI [8]. The important challenge in multilevel inverter is the closed loop control design. SBC is particularly useful in multilevel inverter. Therefore this paper revels the use of SBC in multilevel inverters and presents some investigations on harmonics and closed loop control strategies with respect to equal and unequal voltages. 


\section{Methodology}

The proper control scheme is required for the proposed topology to simulate and hence, a control strategy for the with equal capacitor voltages and independent controls is shown in the below Fig. 1.
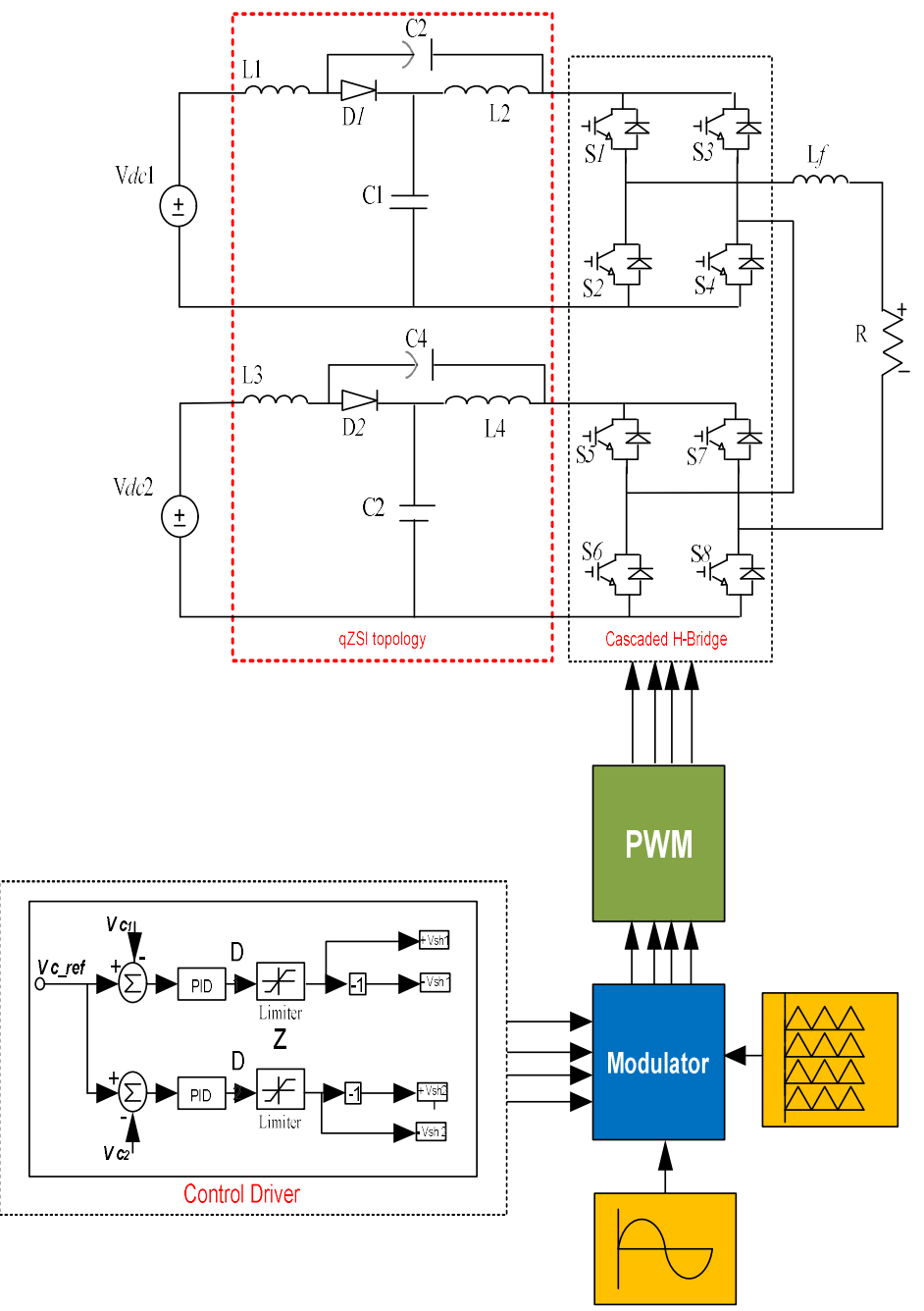

Fig. 1: The Proposed Control Scheme

The capacitor voltage of each module is controlled with the help of a simple proportional-integral-derivative (PID) controller. The output error of the comparator is given to the PID controller after comparing the sensing capacitor voltage with the reference value. And then the control value of Shoot through duty cycle is produced with the output of the PID controller. And to ensure a shoot through duty cycle range a limiter is used. The input output relation with respect to shoot through duty ration $D$ is given in equation 1 below:

$V_{d c}=\frac{1}{1-2 D} \operatorname{Vin}$

\section{Result and Discussions}

In order to validate the proposed SBC method, MATLAB simulation is used. The parameters used for the proposed topology are accordingly, power rating is $1.2 \mathrm{KVA}$, inverter output voltage is $110 V_{r m s}$, output frequency is $50 \mathrm{~Hz}$, Inductors $2 \mathrm{mH}$, capacitor is $1000 \mathrm{mF}$, Load Inductor is $1 \mathrm{mH}$ and switching frequency is $10 \mathrm{KHz}$. 
Helix Vol. 9 (6): 5852- 5856
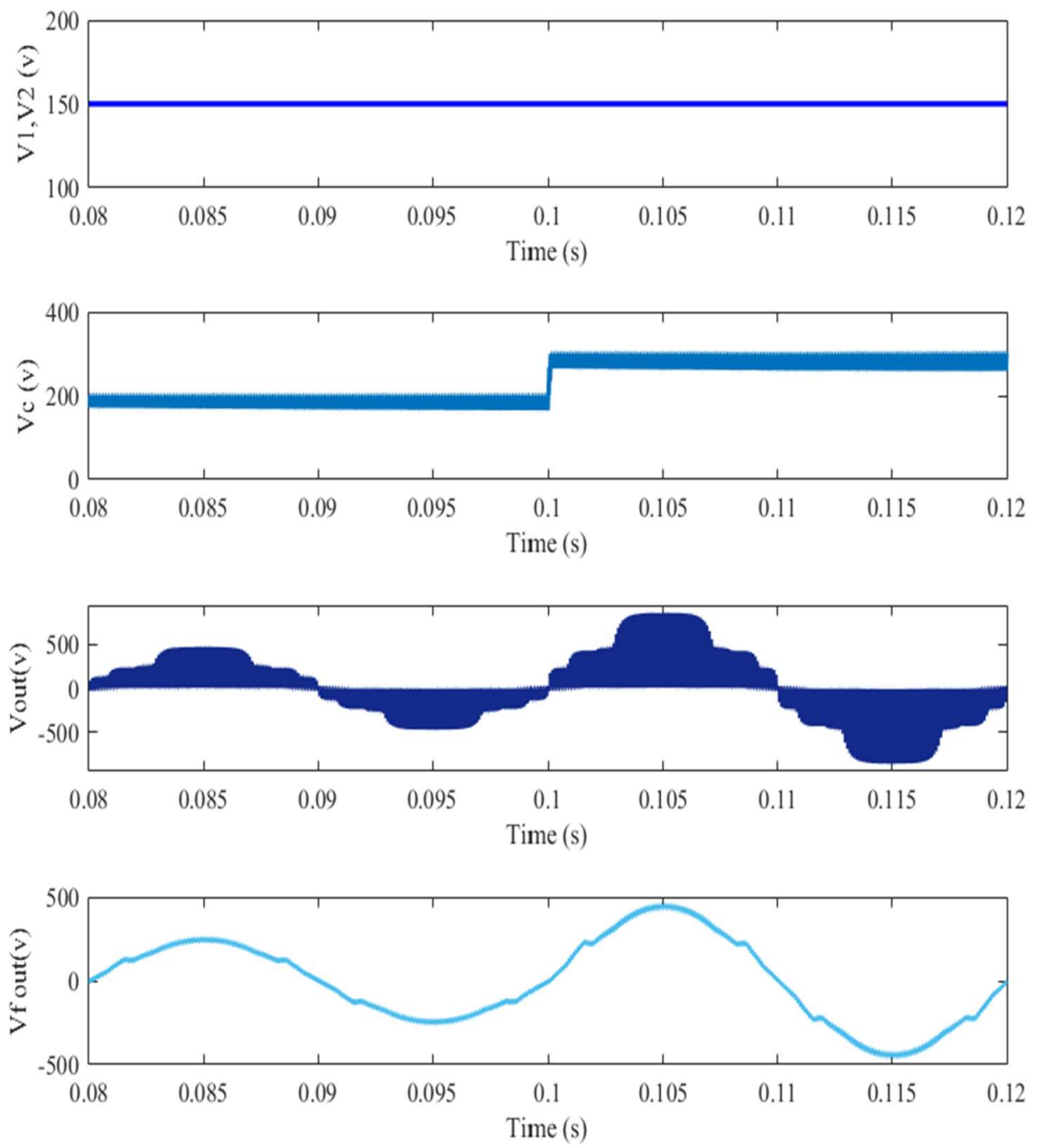

Fig. 2: Simulation Result in Closed Loop when Vdc1 $=$ Vdc2 $=150 \mathrm{~V}$. From Top to Bottom (a) Input Voltages of Both the Modules, (b) Capacitor Voltage, (c) Five-Level Output Voltage Without Filter, (d) Five-Level Output Voltage With Filter

In the closed loop control, here the voltages of both the modules are kept equal that is, $\mathrm{V}_{\mathrm{dcl}}=\mathrm{V}_{\mathrm{dc} 2}=150 \mathrm{~V}$, to investigate the working under balanced input condition. Fig. 2 shows the simulation result in closed loop control of the proposed qZSI based on CHB when both the input voltages are same. The capacitor voltage is boosted in steady state after the step change time in $0.1 \mathrm{~s}$, and the output voltage has five-level. The change in reference input across the capacitor shows the corresponding change in capacitor voltage and consequently the change in amplitude of the output voltage waveform. The inverter output with and without filter are shown at the bottom of this figure. . 

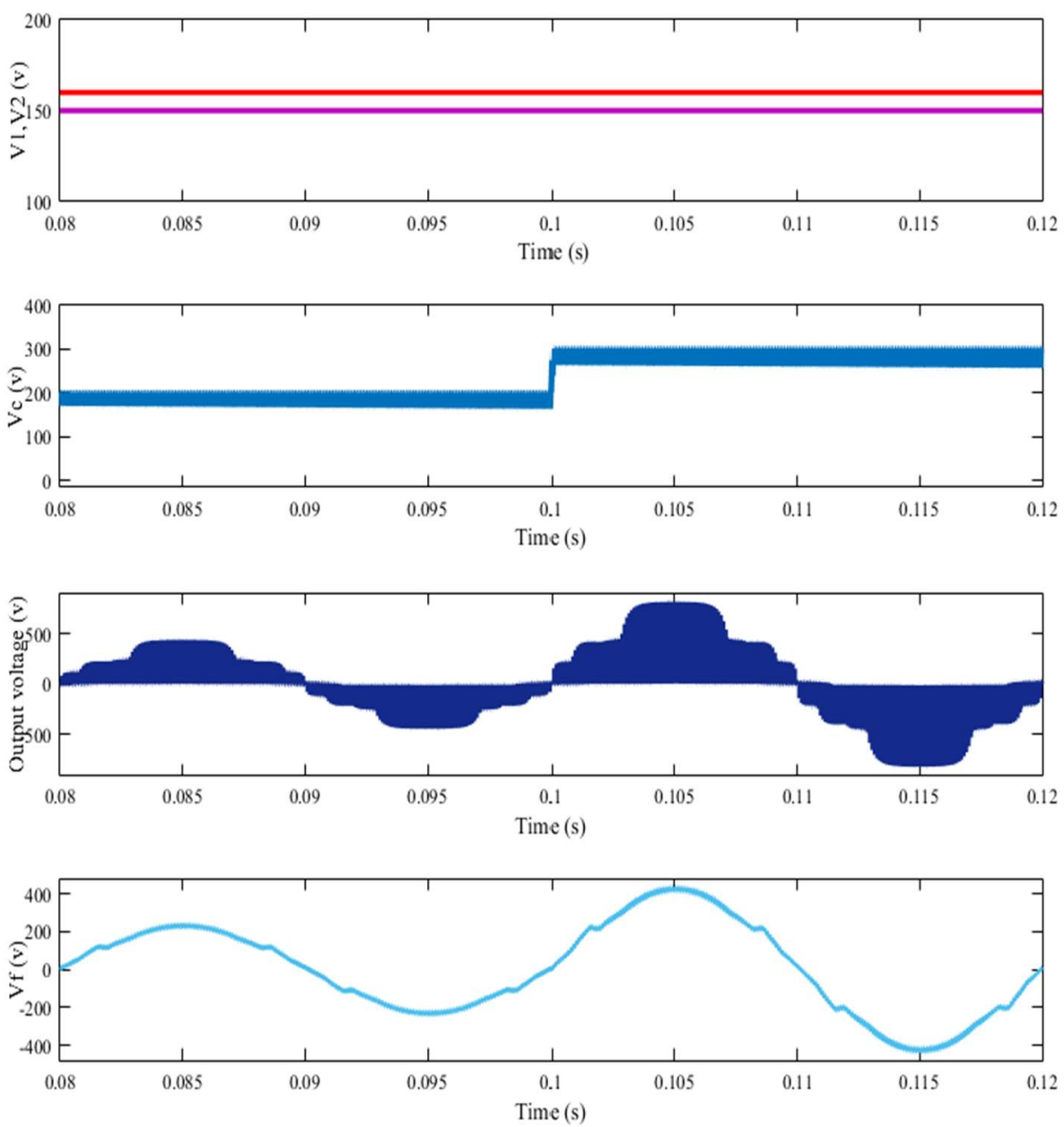

Fig. 3: Simulation Result in Closed Loop when Vdc1 $=150 \mathrm{~V}, \mathrm{Vdc2}=160 \mathrm{~V}$. From Top to Bottom (a) Input Voltages of Both the Modules, (b) Capacitor Voltage, (c) Five-Level Output Voltage Without Filter, (d) FiveLevel Output Voltage With Filter.

In the closed loop control, here the input voltage of the second module is increased and are kept as, $\mathrm{V}_{\mathrm{dc} 1}=150 \mathrm{~V}, \mathrm{~V}_{\mathrm{dc} 2}$ $=160 \mathrm{~V}$, to investigate the working under unbalanced input condition. Fig. 3 shows the simulation result in closed loop control of the proposed qZSI based on CHB when both the input voltages are unequal. The capacitor voltage is boosted in steady state after the step change time in $0.1 \mathrm{~s}$, and the change in reference input across the capacitor shows the corresponding change in capacitor voltage and consequently the change in amplitude of the output voltage waveform. The inverter output with and without filter are shown at the bottom of this figure.

The different values of THD are considering the variation of input voltages in open loop and closed loop, for equal voltage THD is $3.67 \%$ and for unequal input voltage THD is $3.98 \%$.

\section{Conclusions}

1. A Quasi Z source based on cascaded H-bridge five level boost inverter has been simulated in this paper including its closed loop control strategy with the variation in the input dc-voltages under balanced and unbalanced condition.

2. The proposed inverter has the advantage as it has five-level output voltage, the component count decreases and this also has the shoot through immunity.

3. The PWM control strategy with simulation result and THD analysis are shown in this paper of the qZSI based on CHB. The SBC applied to CHB is presented with effective control strategy. 


\section{References}

1. M. K. Nguyen and T. T. Tran, "Quasi cascaded-bridge five-level boost inverter," IEEE Trans. Ind. Electron., vol. 64,no.11, Nov 2017.

2. M. Malinowski, K. Gopakumar, J .Rodriguez , and M.A.P'erez, “A survey on cascaded multilevel inverters,” IEEE Trans. Ind. Electron., vol. 57, no. 7, pp. 2197-2206, Jul. 2010.

3. J. Anderson and F. Peng, "A class of quasi-z-source inverters," in Industry Applications Society Annual Meeting, 2008. IAS '08. IEEE, 2008, pp. 1-7.

4. Y.Yu, G.Konstantinou, B.Hredzak, and V.G.Agelidis, "Operation of cascaded H-bridge multilevel converters for large-scale photovoltaic power plants under bridge failures," IEEE Trans. Ind. Electron., vol. 62, no. 11, pp. 7228-7236, Nov. 2015.

5. R. Uthirasamy, U. S. Ragupathy, V. K. Chinnaiyan, and C. Megha, "Experimentation of boost chopper interfaced cascaded multilevel inverter topology for photo voltaic applications," Int. Rev. Electr. Eng., vol. 9, no. 1, pp. 16-25, 2014.

6. S. G. Kadwane, U. K. Shinde, S. P. Gawande, and R. K. Keshri,"Symmetrical shoot-through based decoupled control of z-source inverter, "IEEE ACCESS 5, 11298-11306, 2017.

7. Umesh Shinde, Sagar Kottagattu, S. G. Kadwane, and S. P. Gawande, "Grid Connected Quasi Z-Source Inverter with Battery", Turkish Journal of Electrical and Computer Engineering, 26 (4), 1847-1859, July 2018.

8. S. G. Kadwane, S. P. Vepa, B. M. Karan and T. Ghose, "Converter Based DC Motor Speed Control Using TMS320LF2407A DSK" IEEE conference on Industrial Electronics and Applications, ICIEA, Singapore, 25-27 May 2006, pp: 117-121.

9. D. Sun, B. Ge, W. Liang, H. Abu-Rub, and F. Z. Peng, "An energy stored quasi-Z-source cascade multilevel inverter-based photovoltaic power generation,", IEEE Trans .Ind. Electron., vol. 62, no.9, pp. 5458-5467, Sep. 2015.

10. M. K. Nguyen, T. V. Le, S. J. Park, and Y. C. Lim, “A class of quasi switched boost inverters,” IEEE Trans. Ind. Electron., vol. 62, no. 3, pp. 1526-1536, Mar. 2015. 